Bio-grafía. Escritos sobre la Biología y su Enseñanza. ISSN 2027-1034

Número Extraordinario. p.p. 224-231

Memorias del Primer encuentro ambiental Universidad, ambiente y sustentabilidad: experiencias y prácticas.

\title{
TRANSPORTE VERDE Y CIUDAD SUSTENTABLE
}

Benavides Melo Julie ${ }^{1}$

\section{Resumen}

El presente artículo pretende reflexionar en torno al impacto ambiental que supone el modelo económico global, junto con el modelo de desarrollo de las ciudades en las cuales estamos inmersos, tanto a nivel latinoamericano como en países industrializados. Ello genera ciudades dispersas, segregadoras y con una calidad de vida limitada en donde los sistemas de transporte terminan siendo ineficaces y altamente contaminantes. Como respuesta a ello y dando una alternativa de solución, se propone un cambio social hacia el paradigma del buen vivir que pasa por la planeación de ciudades más compactas y el posicionamiento de sistemas de transporte alternativo (la bicicleta, por ejemplo) como una alternativa para la movilidad que pueda ayudar a mitigar el impacto ambiental. Se espera que la adopción del conjunto de medidas, permita un tránsito hacia ciudades sustentables.

Palabras Claves: Sustentabilidad, transporte verde, ciudades sustentables.

\section{Abstract}

This article aims to reflect on the environmental impact of the global economic model, together with the development model of the cities in which we are immersed, both in Latin America and in industrialized countries. This creates dispersed, segregated cities with limited quality of life where transport systems end up being ineffective and highly polluting. In response to this and providing an alternative solution, a social change is proposed towards the paradigm of good living that goes through the planning of more compact cities and the positioning of alternative transportation systems (bicycle, for example) as an alternative to Mobility that can help mitigate environmental impact. It is expected that the adoption of the set of measures, allow a transit to sustainable cities.

Keywords: Sustainability, green transport, sustainable cities.

Universidad Pedagógica Nacional. Docente del departamento de Química. SISMA-Semillero de Investigación en Salud y Medio Ambiente. Email: juliebenavidesm@gmail.com 
Bio-grafía. Escritos sobre la Biología y su Enseñanza. ISSN 2027-1034

Número Extraordinario. p.p. 224-231

Memorias del Primer encuentro ambiental Universidad, ambiente y sustentabilidad: experiencias y prácticas.

\section{INTRODUCCIÓN}

La realidad ambiental por la que actualmente atraviesa el planeta es extremadamente preocupante, puesto que ahora estamos expuestos a fenómenos naturales muy agresivos; muchos de ellos producto de nuestra falta de conciencia ambiental, el uso inadecuado de los recursos naturales, la búsqueda de acumulación y/o riqueza y la prevalencia del individuo por encima de sus semejantes y por supuesto, de otras especies.

Todo lo anterior, parece ser producto del modelo económico adoptado a nivel planetario, que como consecuencia produce fuertes impactos en los ecosistemas; tales como la extinción de especies, la deforestación, el agotamiento de cuerpos hídricos, la disminución de la calidad del aire y el cambio climático. Y que se acentúa en los lugares en donde el espacio nativo ha sido reemplazado para dar lugar a la implantación de urbes densificadas con la infraestructura que esto compete y todos los factores asociados que pueden llegar a cobrar relevancia. (Toro, 2010)

Es allí en donde el tema de movilidad urbana empieza a cobrar mayor importancia pues del análisis en cuanto a beneficios e impactos de la infraestructura de transporte, así como las relaciones con el territorio y la economía se revisten de gran importancia y constituyen una rica fuente de investigación, revisión de teorías y necesaria actualización por tratarse de temáticas que viven en constante renovación. (Mollinedo, 2014)

En este contexto, las reflexiones en torno al tema de movilidad se constituyen como una oportunidad pues es una problemática que puede ser abordada desde diferentes disciplinas y perspectivas llegando a conclusiones importantes en muchos de los casos o cayendo en la imposibilidad del desarrollo de una visión multidisciplinaria bien articulada en algunos otros.

Es evidente la importancia que la sociedad le ha dado al tema de la movilidad pues en la mayoría de los casos los elementos asociados al transporte permiten que una sociedad logre tener mejores indicadores de productividad y equidad y los inconvenientes derivados del transporte, 
Bio-grafía. Escritos sobre la Biología y su Enseñanza. ISSN 2027-1034

Número Extraordinario. p.p. 224-231

Memorias del Primer encuentro ambiental Universidad, ambiente y sustentabilidad: experiencias y prácticas.

pueden impactar en mayor o menor medida en la calidad de vida de sus habitantes.

Teniendo en cuenta lo anterior, el mundo actual requiere que el tema de movilidad venga acompañado de la sustentabilidad y que el paradigma social vaya cambiando de a pocos para que al adoptar prioridades diferentes se pueda llegar a privilegiar el bienestar y la permanencia de la raza humana y la mayoría de las especies vivientes que actualmente conocemos. Por ello, se puede posicionar la filosofía del buen vivir como una bandera cuya implementación paulatina permitirá a las sociedades su supervivencia y la garantía de recursos para las futuras generaciones.

\section{OBJETIVOS}

Objetivo general:

Realizar una reflexión en torno a los sistemas de transporte empleados en la actualidad junto con el modelo de ciudad existente y cómo la bicicleta como transporte alternativo se constituye como una herramienta para la promoción de la sustentabilidad.

Objetivos específicos:

Reflexionar frente a los sistemas de transporte que se emplean en la actualidad y el impacto ambiental producido por ellos.

- Comprender la relación entre transporte y modelo de ciudad.

- Visibilizar a la bicicleta como agente de transformación y promotora de la sustentabilidad.

DESARROLLO

Para el desarrollo de la charla se partió de una reflexión sobre el actual modelo de desarrollo y las implicaciones que este tiene en la relación hombre - naturaleza. 
Número Extraordinario. p.p. 224-231

Memorias del Primer encuentro ambiental Universidad, ambiente y sustentabilidad: experiencias y prácticas.

Se puede afirmar que el mencionado modelo de desarrollo, está basado casi exclusivamente en el consumo de recursos que, sin un control aparente, termina por convertirse en insostenible. El crecimiento resulta siendo expansivo, desordenado y acelerado en los sistemas urbanos y el aumento del consumo de recursos que subyace a un interés por capitalizar y acumular, genera una producción de residuos contaminantes que en la mayoría de los casos no son tratados de manera responsable para evitar costos asociados y aumentar las ganancias. Es así como todos estos elementos se conjugan generando condiciones ambientales desfavorables, disminuyendo la calidad de vida de sus habitantes e incrementando la insostenibilidad en la ciudad. (Haughton, 1997.)

Aún más, la tendencia que se presenta actualmente en la que se concibe la urbanización como la creadora de una ciudad difusa, en donde las funciones de la ciudad deben ser separadas para atender bienes y servicios de sus habitantes en áreas distantes entre sí viene siendo altamente cuestionada pues ello demanda largos desplazamientos, ineficiencia y caos para sus habitantes.

Si solo se piensa en el tema de movilidad y su relación con el ambiente, una ciudad difusa provoca un aumento de emisiones de gases contaminantes, de exposición perturbación auditiva, de accidentes y de horas laborales perdidas en desplazamientos. Además de mencionar que el tema del transporte en una ciudad difusa termina creando disfunciones en términos sociales puesto que genera espacios monofuncionales, aumenta el consumo de recursos y segrega a la población según su ingreso, lo que redunda en la perdida de cohesión social e inclusive en el aumento de la inseguridad y

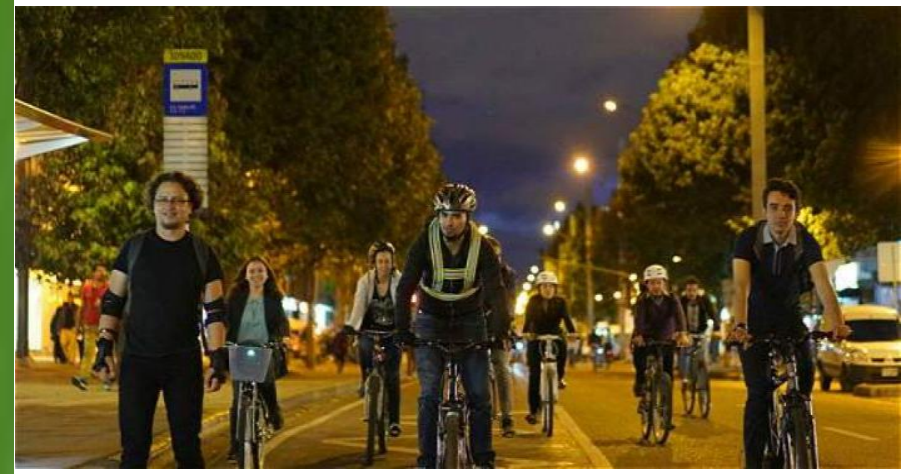

Foto: Héctor Fabio Zamora / EL TIEMPO Imagen tomada de Hechos.com.co 15-12-2016 otras problemáticas sociales asociadas puesto que los ciudadanos de escasos recursos terminan siendo quienes tienen desplazamientos más voluminosos, ingresos más reducidos y muy poco tiempo para compartir en familia por lo que la 
Bio-grafía. Escritos sobre la Biología y su Enseñanza. ISSN 2027-1034

Número Extraordinario. p.p. 224-231

Memorias del Primer encuentro ambiental Universidad, ambiente y sustentabilidad: experiencias y prácticas.

formación y acompañamiento al nivel de sus núcleos familiares termina siendo insuficiente generando una espiral lo suficientemente riesgosa como para que amerite una reflexión a profundidad.

Así, se hace necesario avanzar en la construcción e implementación de un modelo de ciudad diferente en el que se atienda a las disfunciones sociales ya creadas mientras que se asumen los retos de la sociedad contemporánea. En ese sentido y teniendo en cuenta la reflexión y los puntos en contra que se pueden evidenciar en una urbanización difusa, se posiciona un modelo de ciudad compacta y diversa, dado que ello permitiría concebir un aumento de la complejidad, obtener una vida social cohesionada y una plataforma económica más eficiente y competitiva. Adicionalmente, éste modelo de ciudad contribuye a mitigar el impacto ambiental con el que debemos convivir todos los días al interior de las urbes dado el ahorro de tiempo, energía y recursos materiales que produciría una organización diferente. (Burton, 2003)

Para que la mitigación del impacto ambiental sea una realidad y pueda sostenerse en el tiempo, tiene que ir acompañada de una pedagogía adecuada a la ciudadanía para que entienda la relevancia que tiene la protección de los ecosistemas importantes con los que cuenta la ciudad y como éstos actúan en lo cotidiano para el bienestar de todos los individuos que habitan este territorio. Para el caso de Bogotá, por ejemplo, pasa por el posicionamiento del agua como fuente de vida y de desarrollo para los ciudadanos, el cuidado de las fuentes hídricas tales como quebradas, ríos y humedales; la limitación del uso del suelo, así como la defensa de los cerros orientales y la reserva forestal del norte.

Todas esas acciones, sin lugar a dudas, contribuyen a la mitigación y a la generación de una ciudad más sustentable. Sin embargo, un cambio de paradigma, en términos de modelo de ciudad, es difícil porque se trata de un proceso de larga data que conlleva gran esfuerzo institucional, un cambio de pensamiento y una modificación de paradigma. Esto podría darse si se aplicaran conceptos propios de la filosofía del buen vivir y aplicándolos a la organización de las ciudades, de manera que al tomar del medio únicamente lo necesario, se garantice la conservación de recursos para las 
Bio-grafía. Escritos sobre la Biología y su Enseñanza. ISSN 2027-1034

Número Extraordinario. p.p. 224-231

Memorias del Primer encuentro ambiental Universidad, ambiente y sustentabilidad: experiencias y prácticas.

generaciones venideras mientras se disminuyen los indicadores de contaminación al interior de las ciudades.

Mientras todo ello sucede, se tienen que ir realizando acciones que permitan ir generando la transición. Acciones que visibilicen un cambio de conciencia, sirvan como ejemplo para el resto de las personas que habitan el territorio y sean coherentes con la sustentabilidad ambiental, es allí donde aparece la bicicleta. El vehículo del futuro, fue creado durante 1880 y puede constituirse como una alternativa que en paralelo pueda resolver el tema de transporte, contribuya a la disminución de indicadores de contaminación, empodere a la ciudadanía y genere disminución de la segregación en la misma. (Richard Grant / Richard Ballantine, 1992)

El imperio de los autos como medio de trasporte urbano debe finalizar, dando paso a una nueva cultura de movilidad y todo ello solo puede construirse si sumamos muchas manos y millones de pedalazos. Esfuerzos que deben darse desde frentes diversos, es decir, para esto necesitamos la labor de niños, jóvenes, trabajadores, amas de casa, en fin, ciudadanos que sin el distingo de edad, raza, credo, posición social, género, etc se sumen y apuesten decididamente por el uso de la bicicleta.

Hoy por hoy, todos conocemos que la ciudad se asfixia con el tráfico creciente y que los carros se han vuelto dueños y señores del espacio urbano, pues no falta el clásico ejemplo de conductores que toman como parqueadero zonas escolares, el carril derecho de muchas de las vías e incluso las ciclorrutas; el tráfico automovilístico impregna y condiciona nuestra vida diaria pues nos someten a niveles de ruido y emisiones de gases contaminantes que solo ellos determinan y todos nosotros padecemos (hay que ver los pitazos en la calle por tener que esperar dos segundos a un paso cebra por ejemplo o la cantidad de puentes peatonales para evitarles tener que esperar el cambio en un semáforo). Por ello se requiere con
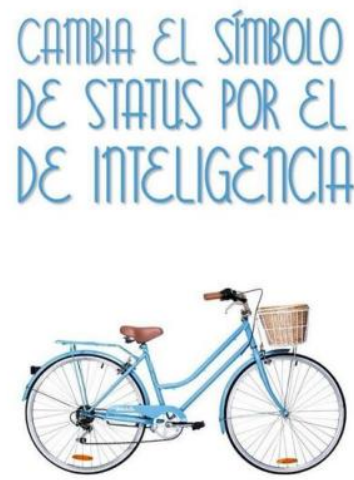

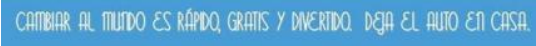

Imagen de Barletta cycles 05-05-2015 
Bio-grafía. Escritos sobre la Biología y su Enseñanza. ISSN 2027-1034

Número Extraordinario. p.p. 224-231

Memorias del Primer encuentro ambiental Universidad, ambiente y sustentabilidad: experiencias y prácticas.

urgencia que, como ya se dice popularmente, las nuevas generaciones cambien su símbolo de estatus por uno de inteligencia y que cada día más y más gente se suba a una bicicleta ( $u$ otro transporte que no requiera combustible fósil) pensando en ser ese héroe anónimo que a pedal va construyendo un planeta diferente.

4 No

Por último y para mostrar como la bici ha sido motor de cambio a lo largo de toda su historia, vale la pena resaltar que ella, no es únicamente un aparato mecánico mediante el cual una persona puede trasladarse de un punto $A$, a un punto $B$, sino que se trata de una maquinita de sueños.

Esa maquinita que fue artífice de una "revolución" en la sociedad de 1880 propiciando la creación del sistema nacional de carreteras estadounidense. Esa que logró empoderar a las mujeres en la década de 1890 brindándoles autonomía, contribuyendo con un cambio de vestimenta que les daba mayor libertad y aumentando el nivel de derechos

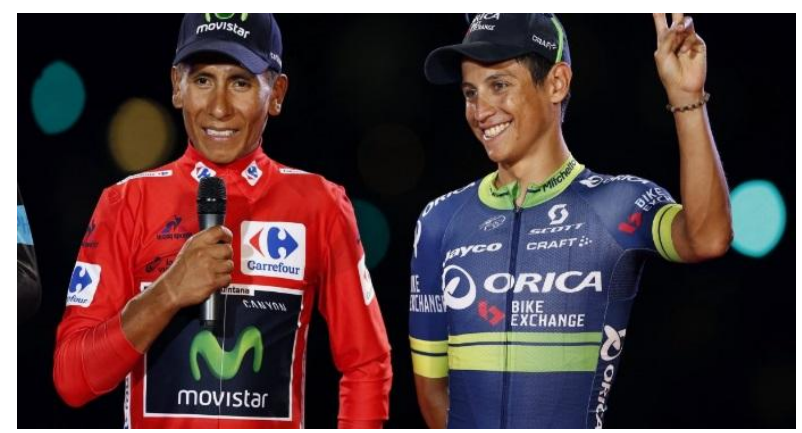

Foto: Miguel Ruíz Morales / Publisport Imagen tomada el 12-12-2016 ciudadanos a las que podían acceder. (Bonafé, 2001) La misma que por los años de 1940 le permitió a Gino Bartali (Pivato, 1980) salvar la vida de alrededor de 800 judíos durante la segunda guerra mundial y bueno, esa que en épocas más recientes, nos ha brindado tantas alegrías con figuras como Lucho Herrera, Fabio Parra, Rigoberto Urán, Nairo Quintana y Esteban Chaves jóvenes humildes que decidieron cambiar algunas de las adversidades con las que contaban en su momento por la convicción, el esfuerzo y la entrega que supone el ciclismo para convertirse en ejemplo de un país como el nuestro en donde muchos jóvenes no cuentan con la misma entereza y terminan por tomar decisiones equivocadas que los llevan a situaciones extremadamente complicadas. Entonces ¿Por qué no usarla como el vehículo que nos conduzca hacia la construcción de ciudades sustentables? 
Bio-grafía. Escritos sobre la Biología y su Enseñanza. ISSN 2027-1034

Número Extraordinario. p.p. 224-231

Memorias del Primer encuentro ambiental Universidad, ambiente y sustentabilidad: experiencias y prácticas.

\section{BibLIOGRAFÍA}

Bonafé, M. G. (2001). El siglo XX. La revolución deportiva de las mujeres. Apunts. Educación física y deportes, 2(64), 63-68.

Burton, E. J. (2003). The compact city: a sustainable urban form? Routledge. Haughton, G. (1997). Developing sustainable urban development models. Cities, 14(4), 189-195.

Mollinedo, C. L. (2014). Movilidad urbana sostenible: un reto para las ciudades del siglo XXI. Economía Sociedad y Territorio.

Pivato, S. (1980). II mondo cattolico e lo sport: Gino Bartali. Belfagor: 35, 227.

Richard Grant / Richard Ballantine. (1992). El Gran Libro de la Bicicleta Texto: Español. Madrid : Editor: El País, Aguilar. .

Toro, J. R. (2010). Environmental impact assessment in Colombia: critical analysis and proposals for improvement. . Environmental Impact Assessment Review, $30(4)$, 247-261. 